\title{
Assisting the New Teacher
}

\author{
J . B . E D M O N S N
}

\section{Dean, School of Education, University of Michigan, Ann Arbor}

$\mathbf{M}$

ANY TEACHERS leave the profession after one year's experience because of their dissatisfaction with teaching conditions or because they are disgusted with their experiences in the community. Other teachers transfer to other systems for much the same reasons.

These losses to the profession are costly, especially at a time when so few new teachers are available as at present. Could such losses be reduced? If so, how?

\section{SHOW CONSIDERATION FOR BEGINNERS}

The beginning teacher deserves special consideration on the part of the administrator. Several years ago the author urged the North Central Association of Colleges and Secondary Schools to adopt a standard designed to protect the beginning teacher from being assigned a full load of work or responsibility for a major school activity.

Although the association did not adopt the proposed standard, a recommendation was made that high schools avoid giving a full load to the inexperienced teacher and that they extend special supervisory assistance to the beginner.

It is the writer's opinion that teachers new to a school system need such assistance by administrators as is implied in the following statements.

1. Help should be afforded in finding an attractive place to live, special attention being paid to the protection of the teacher against undesirable neighborhoods and against the misfortune of taking a room in the home of a town gossip.

2. Advice should be given the teacher during the summer months regarding proposed teaching assignments, including information regarding the school's basic textbooks, the course of study, and similar matters.

3. The teacher should be invited to come to the community a day or two before the opening of school in order to obtain living quarters and to become somewhat acquainted with the school and the community.

4. An interpretation of the disciplinary policies of the school should be given to the teacher in order that she may avoid extremes in disciplinary measures.

5. Former teachers should be urged to extend help to newcomers rather than stand on the side lines and watch the beginner struggle with annoying problems.

6. Encouragement should be given to teachers to organize social and recreational activities in which new teachers should have adequate opportunities to participate. 
7. New teachers should receive sympathetic help from the supcrvisory staff before major difficulties are encountered.

8. A suggestion should be given to community organizations, such as churches and clubs, that the new teacher faces the task of "making good" in the school and that this requires that she or he avoid heavy outside demands during the greater part of the first year.

\section{GIVE THEM LIGHTER ASSIGNMENTS}

In addition to these kinds of assistance, inexperienced teachers should be given a lighter assignment of work. The practice of assigning work to beginners that experienced teachers do not want is unfair, as is the practice of transferring to beginners the more troublesome pupils.

In assisting newcomers to become adjusted, nothing will take the place of a genuine spirit of helpfulness on the part of school officials and experienced teachers. A co-operative attitude develops in the beginner a feeling of security and such a feeling aids morale. Beginning teachers are under greater strain than are other teachers and helpful diversions should be provided. Confidence in associates provides a needed relief from excessive personal responsibility and promotes a desirable quality of good feeling.

A planning conference in advance of the opening of school provides a valuable service to new teachers as well as a useful service to former teachers. It should not be difficult to convince a board of education that the two or more days devoted to such a conference is a good investment of the necessary time and money.

\section{HOLD PRE-SCHOOL CONFERENCES}

Unfortunately many schools open on a selected Monday without any preliminary conferences. It is not surprising that some beginning teachers look back to the first week of school with the feeling that they passed through a nerve-racking experience which they hope they will never have to repeat. When new teachers have this feeling, it is an indictment of the administrator.

In the effective adjustment of new teachers to the school and the community, the school administrator also has an unusual opportunity to protect the interests of pupils because unhappy and disgruntled teachers are never good persons to place in charge of pupils. Effective adjustment of teachers will also decrease teacher turnover and will improve morale.

What are your policies for conserving the enthusiasm, professional zeal, and morale of your new teachers? If you do not have any plans for accomplishing these ends, the formulation of such plans is urged before school opens as a means of ensuring a more satisfying year of work for your new teachers. 